\title{
Controlling Dielectric and Magnetic Properties of PVdF/Magnetite Nanocomposite Fibre Webs
}

\author{
A. P. Venugopal, ${ }^{1}$ O. Cespedes, ${ }^{2}$ and S. J. Russell ${ }^{1}$ \\ ${ }^{1}$ Nonwovens Research Group, Centre for Technical Textiles, School of Design, University of Leeds, Leeds LS2 9JT, UK \\ ${ }^{2}$ Condensed Matter Physics Group, School of Physics and Astronomy, University of Leeds, Leeds LS2 9JT, UK \\ Correspondence should be addressed to A. P. Venugopal; arunprasad.venugopal@gmail.com
}

Received 9 September 2013; Revised 26 March 2014; Accepted 26 March 2014; Published 27 April 2014

Academic Editor: Yulin Deng

Copyright (c) 2014 A. P. Venugopal et al. This is an open access article distributed under the Creative Commons Attribution License, which permits unrestricted use, distribution, and reproduction in any medium, provided the original work is properly cited.

\begin{abstract}
The ability of filtration and separation media containing fibres to remove impurities from oil, water, and blood can be enhanced using magnetic fields. The ability to regulate the dielectric and magnetic behaviour of fibrous webs in terms of superparamagnetic or ferromagnetic properties by adjusting material composition is fundamental to meeting end-use requirements. Electrospun fibres were produced from PVdF (polyvinylidene fluoride) and nanomagnetite $\left(\mathrm{Fe}_{3} \mathrm{O}_{4}\right.$ nanoparticles) from solutions of PVdF in dimethylacetamide containing $\mathrm{Fe}_{3} \mathrm{O}_{4}$ nanoparticle contents ranging from 3 to $10 \mathrm{wt} \%$. Fibre dimensions, morphology, and nanoparticle agglomeration were characterised by environmental scanning electron microscopy (ESEM) and field emission gun transmission electron microscopy (FEGTEM). Dielectric behaviour of the fibre webs was influenced by web porosity and the $\mathrm{Fe}_{3} \mathrm{O}_{4}$ nanoparticle content. Impedance analysis of the webs indicated an increase in dielectric constant of $\sim 80 \%$ by the addition of $10 \mathrm{wt} \%$ $\mathrm{Fe}_{3} \mathrm{O}_{4}$ nanoparticles compared to $100 \mathrm{wt} \%$ PVdF. The dielectric constants of the webs were compared with those obtained from the theoretical mixing models of Maxwell and Lichtenecker. Vibrating sample magnetometer (VSM) magnetisation measurements indicated a blocking temperature above $300 \mathrm{~K}$ suggesting ferrimagnetic rather than superparamagnetic behaviour as a result of $\mathrm{Fe}_{3} \mathrm{O}_{4}$ nanoparticle agglomeration within fibres.
\end{abstract}

\section{Introduction}

Magnetic materials in the form of submicron diameter fibres can be used in high performance filtration and separation media to remove impurities from liquids such as oil, water, and blood. To support industrial development, it is important to understand how to control the dielectric and magnetic behaviour of the submicron fibres so that the filtration or separation device is able to function satisfactorily.

Currently, submicron fibres can be produced by various methods including fibrillation $[1,2]$, splitting of bicomponent fibres [3], melt blowing [4], electrospinning [5-7], centrifugal and force spinning, or combined processes [8-10]. Of these methods, electrospinning has been widely used to convert different thermoplastic engineering polymers into submicron and nanofibres $[6,11]$.

Processes such as sol-gel assisted electrospinning or polymer-nanocomposite electrospinning can be used to manufacture magnetic fibres. The sol-gel route has been used to prepare composite fibres of nickel ferrite [12], $\mathrm{Ni}_{0.5} \mathrm{Zn}_{0.5} \mathrm{Fe}_{2} \mathrm{O}_{4}$ [13], and substituted strontium ferrite $\mathrm{SrRe}_{0.6} \mathrm{Fe}_{11.4} \mathrm{O}_{19}(\mathrm{Re}=\mathrm{La}, \mathrm{Ce})$ [14]. Magnetic copper ferrite fibres prepared by electrospinning have also been reported [15] and $\mathrm{Wu}$ et al. [16] reported electrospun ferromagnetic fibres based upon $\mathrm{Fe}, \mathrm{Co}$, and $\mathrm{Ni}$ with diameters of $25 \mathrm{~nm}$.

Using the polymer-nanocomposite route, a polymer matrix is combined with appropriate particulate fillers such as $\mathrm{Fe}_{3} \mathrm{O}_{4}$ nanoparticles to prepare films and fibres. Previously investigated polymer matrices for embedding $\mathrm{Fe}_{3} \mathrm{O}_{4}$ nanoparticles include polyvinyl alcohol (PVA) [17, 18], polymethyl methacrylate (PMMA) [19], polyacrylonitrile (PAN) [20], polyvinylpyrrolidone (PVP) [21], polyethylene oxide (PEO) [22], and PVdF [23-25]. Specifically in relation to the manufacture of fibres, Barrera et al. [22] reported the fabrication of PEO fibres containing discrete magnetic domains using a modified electrospinning apparatus. Magnetite and cobalt ferrite nanoparticles were synthesized and 
coated with thiolated PEO and then suspended in a 12 wt\% PEO-in-water solution. Polymer-nanocomposite fibres with diameters as small as $200 \mathrm{~nm}$ were then produced by electrospinning. PVdF has attracted considerable research interest in the preparation of submicron diameter fibre assemblies because of its ionic conductivity, electrochemical stability, and piezo-electric properties [26, 27], enabling fibrous polymer electrolytes and battery separators to be fabricated by electrospinning $[28,29]$. As a relatively inert material, PVdF is extensively utilised by industry in the manufacture of membrane filters including hollow fibre membranes for liquid filtration. Although previous research has been conducted on thin films, only a few studies have been reported on the properties of electrospun PVdF and PVdF copolymer fibres containing $\mathrm{Fe}_{3} \mathrm{O}_{4}$ nanoparticles in respect to superparamagnetic or ferrimagnetic behaviour $[23$, 25, 30]. Yang et al. [23, 30] prepared electrospun webs from spinning solutions of $20 \mathrm{wt} \%$ of polyvinylidene fluoride-cotetrafluoroethylene (PVdF-TeFE) dissolved into a mixture of dimethylformamide and 2-butanone with $5 \mathrm{wt} \%$ and $10 \mathrm{wt} \%$ of dispersed 20-30 nm $\mathrm{Fe}_{3} \mathrm{O}_{4}$ nanoparticles. Results were reported for the resulting fibre webs that showed that the $\mathrm{Fe}_{3} \mathrm{O}_{4}$ nanoparticle content influenced dielectric properties, but the data pertained to a copolymer of PVdF-TeFE containing $19 \%$ of the TeFE monomer rather than pure PVdF.

Accordingly, the goal of this paper is to generate a more detailed understanding of the dielectric and specific magnetic saturation properties of pure $\mathrm{PVdF}$ and $\mathrm{Fe}_{3} \mathrm{O}_{4}$ electrospun fibre webs that contain different nanoparticle loadings and to determine the link between measured and calculated dielectric values, specifically in relation to porous media, rather than films. This data is required to enable the assembly of improved filter and separation media in the future.

\section{Materials and Methods}

2.1. Materials. A medium viscosity $\left(M_{w}=352 \times 10^{3} \mathrm{~g} \mathrm{~mol}^{-1}\right)$ polyvinylidine fluoride ( $\mathrm{PVdF})$ homopolymer was industrially sourced (1010 grade, Solef, Tavaux, France). Nonmagnetised nanoparticles of $\geq 98 \% \mathrm{Fe}_{3} \mathrm{O}_{4}$ determined by trace metal analysis $\left(\mathrm{Fe}_{3} \mathrm{O}_{4}\right.$, Sigma-Aldrich, Poole, UK) had a mean particle size of $28.4 \mathrm{~nm}$ with minimum and maximum particle sizes of $10 \mathrm{~nm}$ and $50 \mathrm{~nm}$, respectively, as determined by TEM. These particles were free from ligands or stabilising ions over the surface. Spinning solutions were prepared from dimethylacetamide (DMAc) (Sigma-Aldrich, Poole, UK), which is a known solvent for PVdF.

2.2. Preparation of Linear Nanocomposite Fibre Webs. A $20 \mathrm{wt} \% \mathrm{PVdF}$ solution in DMAc was prepared into which $\mathrm{Fe}_{3} \mathrm{O}_{4}$ nanoparticles of $3 \mathrm{wt} \%, 5 \mathrm{wt} \%$, and $10 \mathrm{wt} \%$ were dispersed. Spinning solutions were sonicated for $60 \mathrm{~min}$ at a frequency of $40 \mathrm{KHz}$ to reduce nanoparticle agglomeration. Electrospinning was conducted using a polymer flow rate of $0.6 \mathrm{~mL} / \mathrm{hr}$ at an applied voltage of $20 \mathrm{kV}$ with a capillary tip to collector distance of $0.13 \mathrm{~m}$. The fibres were spun onto a target of $0.1 \mathrm{~m} \times 0.1 \mathrm{~m}$ aluminium foil to form a self-supporting web. The ambient temperature and humidity within the fume cupboard were $20^{\circ} \mathrm{C}$ and $60 \%$, respectively. Environmental scanning electron microscopy (Phillips XL30 ESEM, Eindhoven, Netherlands) was utilised to verify the uniformity of the as-spun fibres and freedom from structural defects such as beads and fibre bundles.

2.3. Dimensional Characterisation of Nanoparticles. The nanoparticles and as-spun fibres were probed using a thermally assisted field emission gun (FEG) TEM (TECNAI TF20, FEI, Eindhoven, Netherlands) operating at $197 \mathrm{kV}$ (point resolution of $0.24 \mathrm{~nm}$ ) equipped with a UTW Oxford Instruments EDX detector. Mean nanoparticle size distributions were determined directly from the TEM images. After dimensional calibration, measurement of nanoparticle sizes was conducted by image analysis with the inbuilt scale option (Image Pro V 6.2) and the results were directly exported to Microsoft Excel.

2.4. Web Porosity. Web porosity was approximated from ESEM (Phillips XL-30 ESEM) micrographs of each web sample. Binary images (*.bmp format) were prepared by image thresholding such that porosity $(P)$ could then be determined from the mean intensity of the image, distinguishing between the solid and air fractions of the web represented by either black or white pixels (1):

$$
P=\left(1-\frac{n}{N}\right) \times 100,
$$

where $n$ is the number of white pixels (pores) and $N$ is the total number of pixels in the binary image. Micrographs were obtained at an accelerating voltage of $20 \mathrm{kV}$ with a spot size of $4 \mathrm{~nm}$ and a working distance of $5 \mathrm{~mm}$.

2.5. Dielectric Behaviour. The dielectric constant $\varepsilon$ for each sample was calculated using

$$
\varepsilon=\frac{C d}{\varepsilon_{0} A},
$$

where $C$ is the capacitance, $d$ is the plate separation, $A$ is area of the plates, $\varepsilon_{0}$ is the dielectric constant of free space $\left(8.854 \times 10^{-12} \mathrm{~F} / \mathrm{m}\right)$, and $\varepsilon$ is the dielectric constant of the bulk structure. The capacitance of each electrospun web sample was measured by an impedance analyser (Solartron 1260, Solartron Analytical, Farnborough, UK) at room temperature. The plate separation was determined by the mean thickness of the web as measured directly by ESEM. Electrospun samples of $100 \mathrm{wt} \% \mathrm{PVdF}$ and $\mathrm{PVdF}$ polymer nanocomposites containing $3 \mathrm{wt} \%, 5 \mathrm{wt} \%$, and $10 \mathrm{wt} \%$ of $\mathrm{Fe}_{3} \mathrm{O}_{4}$ nanoparticles were analysed.

Corresponding dielectric constants were also calculated based upon Maxwell's rule of mixtures [31] (see, (3)) and Lichtenecker's logarithmic mixing model [32] (see (4)). Of the various mixture models available those of Maxwell and Lichtenecker have been reported to be particularly applicable to porous materials such as electrospun webs [33]. Other models including those of Bruggeman and Maxwell-Garnett [34] are applicable for composite materials containing spherical 
inclusions. The Maxwell model has been previously applied to materials with a uniformly connected pore structure, while the Lichtenecker model is claimed to be more applicable to those that are randomly connected [32]. Since the electrospun webs produced in the present work were expected to be porous and randomly oriented both models were evaluated. The Maxwell mixture equation can be written as

$$
\varepsilon=\frac{v_{m} \varepsilon_{m}\left\{2 / 3+\varepsilon_{p} / \varepsilon_{m}\right\}+v_{p} \varepsilon_{p}}{v_{m}\left\{2 / 3+\varepsilon_{p} / 3 \varepsilon_{m}\right\}+v_{p}},
$$

where $v_{m}$ and $v_{p}$ are the volume fractions of the solid material and voids (air), respectively, and $\varepsilon_{m}$ and $\varepsilon_{p}$ are the corresponding dielectric constants for these components. The Lichtenecker logarithmic equation may be expressed as

$$
\ln \varepsilon=v_{m} \ln \varepsilon_{m}+v_{i} \ln \varepsilon_{i}+v_{p} \ln \varepsilon_{p},
$$

where $\varepsilon$ is the dielectric constant of the entire material, $v_{m}$, $v_{i}, v_{p}$ are the volume fractions of the polymer, iron oxide, and voids, respectively, and $\varepsilon_{m}, \varepsilon_{i}, \varepsilon_{p}$ are the corresponding dielectric constants. The void fraction (porosity) was determined from the weight and thickness of the web. The thickness was measured directly from sections of the web observed by ESEM.

2.6. Magnetic Behaviour. Electrospun webs were characterised by means of a vibrating sample magnetometer (VSM) (Oxford Instruments, Abingdon, UK) operating at $55 \mathrm{~Hz}$ with vibration amplitude of $1.5 \mathrm{~mm}$. The magnetic field is generated by a pair of superconducting coils immersed in a liquid helium reservoir, and the sample temperature was controlled via a PID loop with a heating element and a valve connecting the sample space with the reservoir. Typical noise levels were below $10 \mu \mathrm{emu}$ or $1 \%$ of the signal, with temperature stability better than $50 \mathrm{mK}$ and a maximum sample moment of the order of several hundred memu.

\section{Results and Discussion}

3.1. Incorporation of $\mathrm{Fe}_{3} \mathrm{O}_{4}$ Nanoparticles. All three (3 wt\%, $5 \mathrm{wt} \%$, and $10 \mathrm{wt} \%) \mathrm{Fe}_{3} \mathrm{O}_{4}$ nanoparticle contents were found to disperse in the $20 \mathrm{wt} \% \mathrm{PVdF}$ polymer solution such that electrospun webs could be produced containing continuous fibres with few discernible bead defects (Figure 1). Previously it has been reported that fibre diameter and fibre morphology can be sensitive to increasing $\mathrm{Fe}_{3} \mathrm{O}_{4}$ nanoparticle content in electrospun fibres. Yang et al. [23, 30] reported a decrease in mean diameter of $\mathrm{PVdF}-\mathrm{TeFE} / \mathrm{Fe}_{3} \mathrm{O}_{4}$ electrospun fibres as the nanoparticle content increased. The same trend was observed in the $\mathrm{PVdF} / \mathrm{Fe}_{3} \mathrm{O}_{4}$ electrospun samples produced in the production of the present set of samples [35]. Furthermore Wang et al. [36] have shown that the morphology and diameter of $\mathrm{PAN} / \mathrm{Fe}_{3} \mathrm{O}_{4}$ (particle size $=8 \mathrm{~nm}$ ) electrospun fibres were strongly dependent upon the PAN concentration and salt additives in the spinning solution. In Figure 1, it is evident that the continuous $\mathrm{PVdF} / \mathrm{Fe}_{3} \mathrm{O}_{4}$ fibres obtained did not appreciably change in terms of morphology as the fraction of $\mathrm{Fe}_{3} \mathrm{O}_{4}$ nanoparticles increased from 0 to $10 \mathrm{wt} \%$.

Prior to electrospinning, the mean size of the $\mathrm{Fe}_{3} \mathrm{O}_{4}$ nanoparticles was $28.4 \mathrm{~nm}$. Electrospun samples were analysed to determine the degree to which mean particle size within the fibre corresponded to that of the original size prior to spinning. TEM analysis revealed distributed agglomerations of $\mathrm{Fe}_{3} \mathrm{O}_{4}$ nanoparticles with a mean diameter of $52.7 \mathrm{~nm}$ and $38.2 \mathrm{~nm}$ for unsonicated and sonicated spinning solutions, respectively (Table 1). Individual agglomeration sizes up to $93 \mathrm{~nm}$ were also observed some of which extended beyond the external boundaries of the fibres, creating irregular fibre morphology (Figure 2). Uneven fibre morphologies and difficulties in dispersing ca. $8 \mathrm{~nm}$ diameter $\mathrm{Fe}_{3} \mathrm{O}_{4}$ nanoparticles in PVA nanofibres were also reported by Chung et al. [17]

The problem of nanoparticle agglomeration is a wellknown phenomenon leading to problems such as reduced fibre tensile strength. Minimisation of nanoparticle agglomeration is not straightforward [37-41]. In relation to nanoparticles that can be magnetised, approaches for improving nanoparticle dispersion include sonication of the polymer solution [42, 43], silica addition [44], steric functionalisation of magnetite in an organic solvent [19], and the placement of magnets in close proximity to the collector during electrospinning [45]. Silica aids magnetic nanoparticle dispersion by reducing the interparticle attraction (residual magnetic attraction) between the nanoparticles but after spinning it remains as an unwanted contaminant within the fibres. The propensity to agglomerate is influenced by the viscosity of polymer solution and by surface functionalisation. Since the viscosity of the PVdF polymer solution was relatively high $(1200 \mathrm{cP})$, particles could be retained in suspension for 2 to $3 \mathrm{hr}$ and the nanoparticles were not premagnetised or surface-functionalised. In the present study, no stabilising agents were used and extended sonication $(t=60 \mathrm{~min})$ was adopted to promote nanoparticle dispersion in the solution. Before electrospinning, the $\mathrm{Fe}_{3} \mathrm{O}_{4}$ nanoparticles sizes varied from $10 \mathrm{~nm}$ to $50 \mathrm{~nm}$ with a mean size of $28.4 \mathrm{~nm}$. Sonication of the spinning solution reduced the mean $\mathrm{Fe}_{3} \mathrm{O}_{4}$ particle size in the as-spun fibres from $52.7 \mathrm{~nm}$ to $39.2 \mathrm{~nm}$ (Table 1). Sonication resulted in improved dispersion of particles, effectively redistributing the particles throughout the fibre volume (Figure 3).

In terms of fibre morphology, nanoparticle agglomeration is normally considered disadvantageous, but in the present work it is conceivable that agglomeration could also influence the ferrimagnetic properties of samples by holding greater magnetic moment than a single particle. Thus, the degree of agglomeration may be utilised as a means of controlling dielectric and magnetic behaviour in the fibre web. Agglomeration of nanoparticles can be affected by the use of high filler concentrations even when the fillers are coated to prevent mutual interaction [46]. Interparticle attraction and agglomeration can also be influenced by magnetic behaviour. Superparamagnetism in ferrites below a critical diameter has previously been reported to prevent self-agglomeration [47]. 


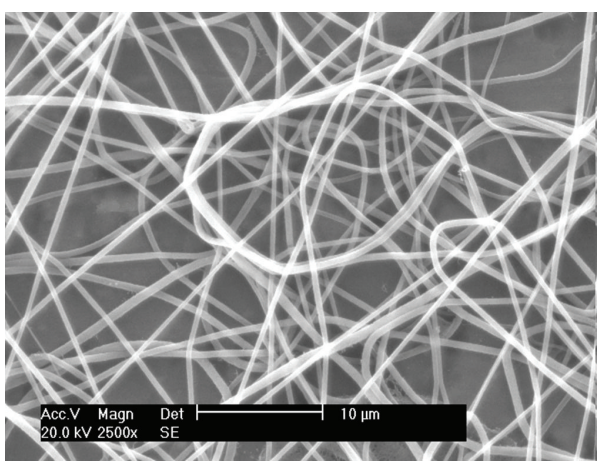

(a) $P=0.83$

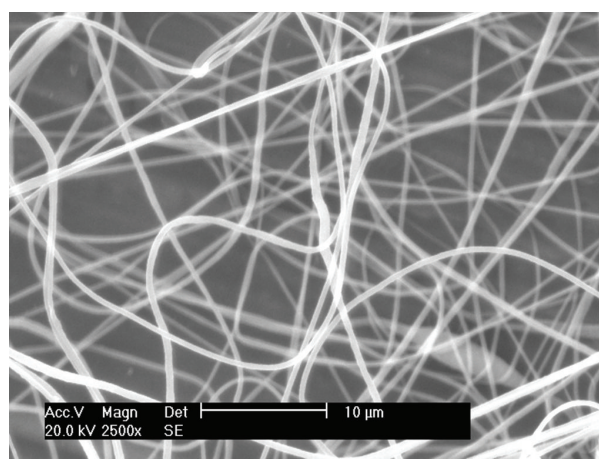

(c) $P=0.80$

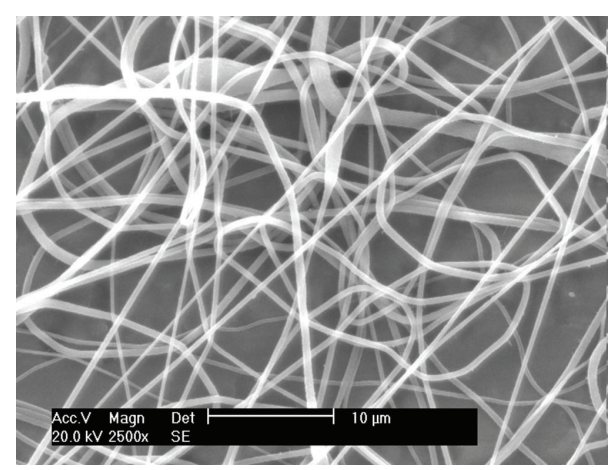

(b) $P=0.82$

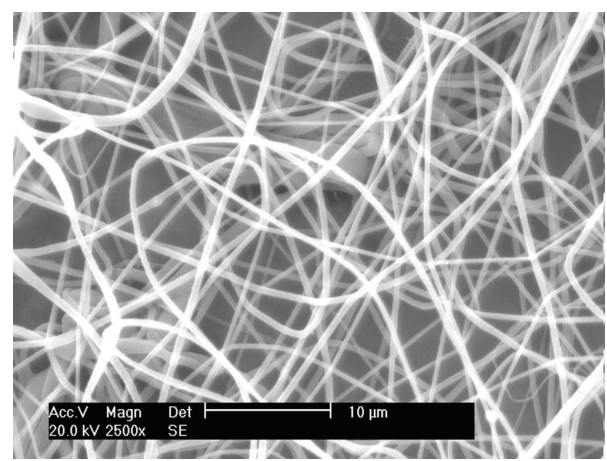

(d) $P=0.79$

FIgure 1: SEM images of $20 \mathrm{wt} \% \mathrm{PVdF}$ and $\mathrm{PVdF} / \mathrm{Fe}_{3} \mathrm{O}_{4}$ fibre webs. Applied voltage: $22 \mathrm{kV}$; flow rate: $0.6 \mathrm{~mL} \mathrm{hr}{ }^{-1}$ : (a) $100 \% \mathrm{PVdF}$; (b) $\mathrm{PVdF} / 3$ wt $\% \mathrm{Fe}_{3} \mathrm{O}_{4}$; (c) $\mathrm{PVdF} / 5$ wt $\% \mathrm{Fe}_{3} \mathrm{O}_{4}$; (d) $\mathrm{PVdF} / 10$ wt $\% \mathrm{Fe}_{3} \mathrm{O}_{4} ; P$ = porosity.

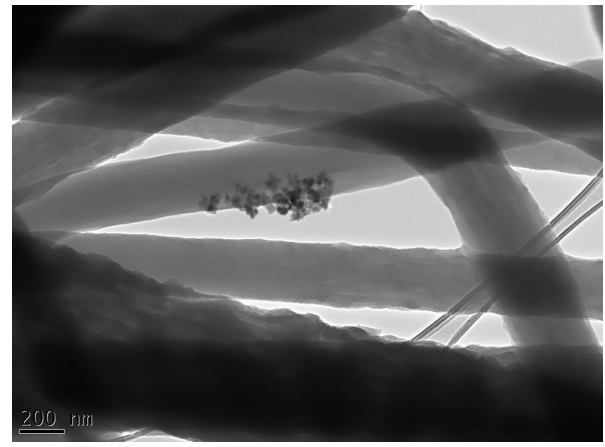

(a)

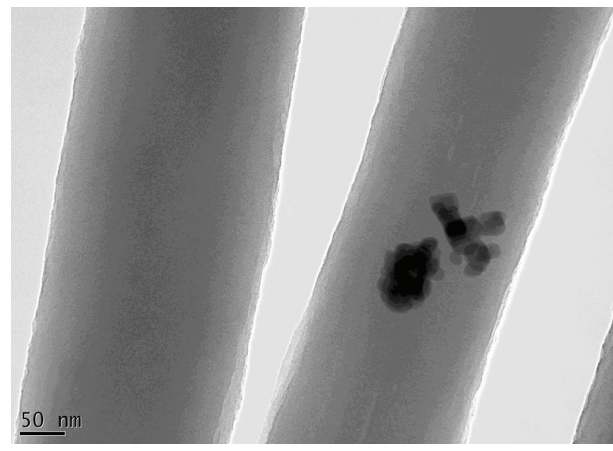

(b)

Figure 2: TEM images of PVdF/5 wt $\% \mathrm{Fe}_{3} \mathrm{O}_{4}$ fibres. (a) Protruding $\mathrm{Fe}_{3} \mathrm{O}_{4}$ nanoparticle agglomeration. (b) Internal $\mathrm{Fe}_{3} \mathrm{O}_{4}$ nanoparticle agglomeration.

3.2. Dielectric Constant. The dielectric constant of Solef PVdF polymer ranges from four to twelve in the frequency range $100 \mathrm{~Hz}$ to $100 \mathrm{kHz}$. Figure 4 shows that markedly lower mean dielectric constants were obtained for the as-spun electrospun PVdF webs of 1.25 (100 wt\% PVdF)-2.25 (PVdF/10 wt\% $\mathrm{Fe}_{3} \mathrm{O}_{4}$ ) compared to the solid PVdF polymer. This is due to the high porosity of the webs ( $P=0.79$ to 0.83 , Figure 1$)$. It is evident that the dielectric constant of electrospun $\mathrm{PVdF} / \mathrm{Fe}_{3} \mathrm{O}_{4}$ webs will be sensitive to large changes in web porosity. This is because the webs can be viewed as multiphase materials consisting of three phases: polymer, nanoparticles, and a large void or air fraction. As is the case with the majority of nonwoven assemblies the void fraction has a large influence on the dielectric behaviour and industrially, control of void fraction is a commonly utilised means for modifying the dielectric behaviour of electrically conductive materials. The influence of porosity on the dielectric constant of electrospun $\mathrm{PVdF} / \mathrm{Fe}_{3} \mathrm{O}_{4}$ nanoparticle fibre webs is illustrated in Figure 5 based upon the theoretical mixing models of (3) and (4). Linear and exponential relationships between dielectric constant and porosity were obtained for the Maxwell and Lichtenecker models, respectively (Figure 5), which are in 
TABLE 1: Mean size of $\mathrm{Fe}_{3} \mathrm{O}_{4}$ nanoparticles before and after inclusion within electrospun fibres.

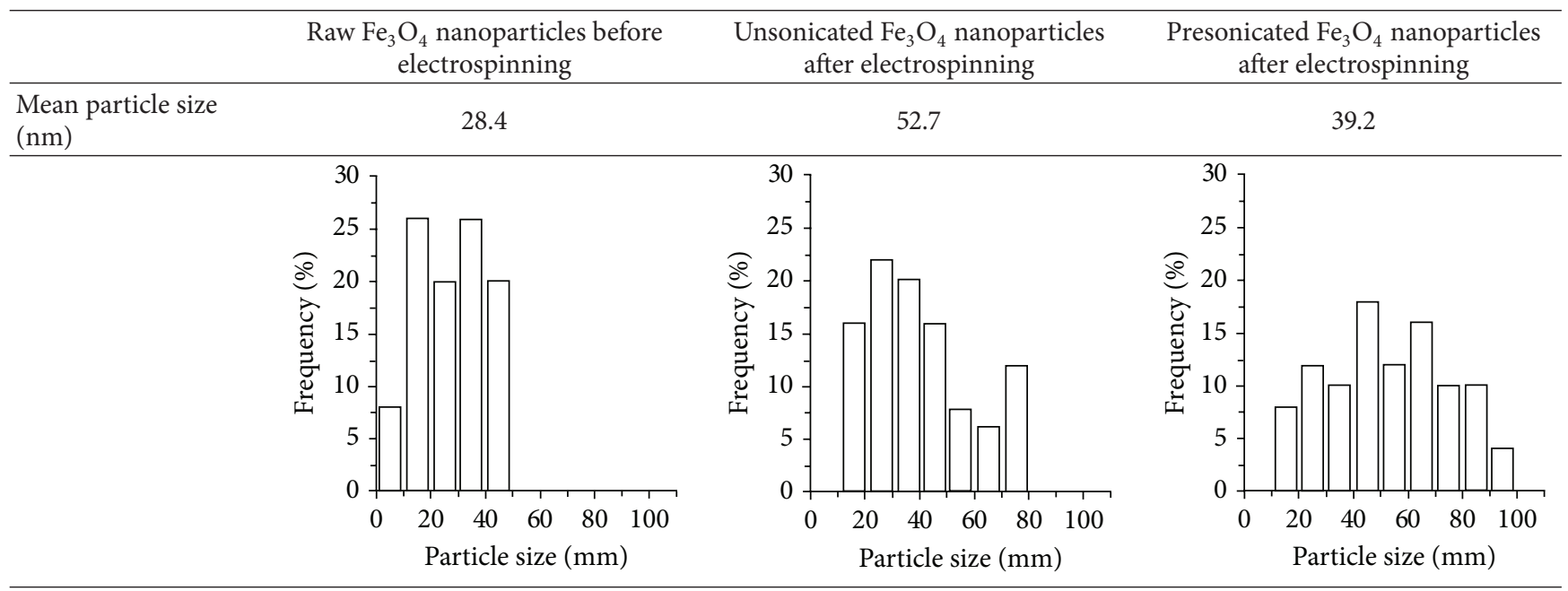

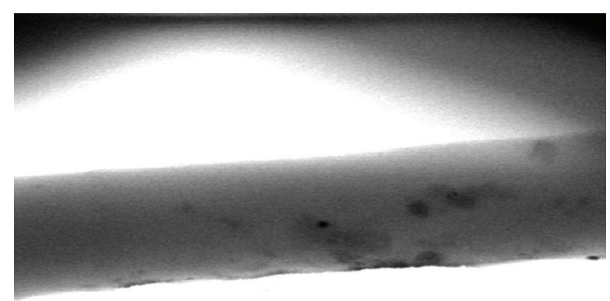

$200 \mathrm{~nm}$

Figure 3: Dispersion of $\mathrm{Fe}_{3} \mathrm{O}_{4}$ nanoparticles inside a fibre after sonication $(60 \mathrm{~min})$.

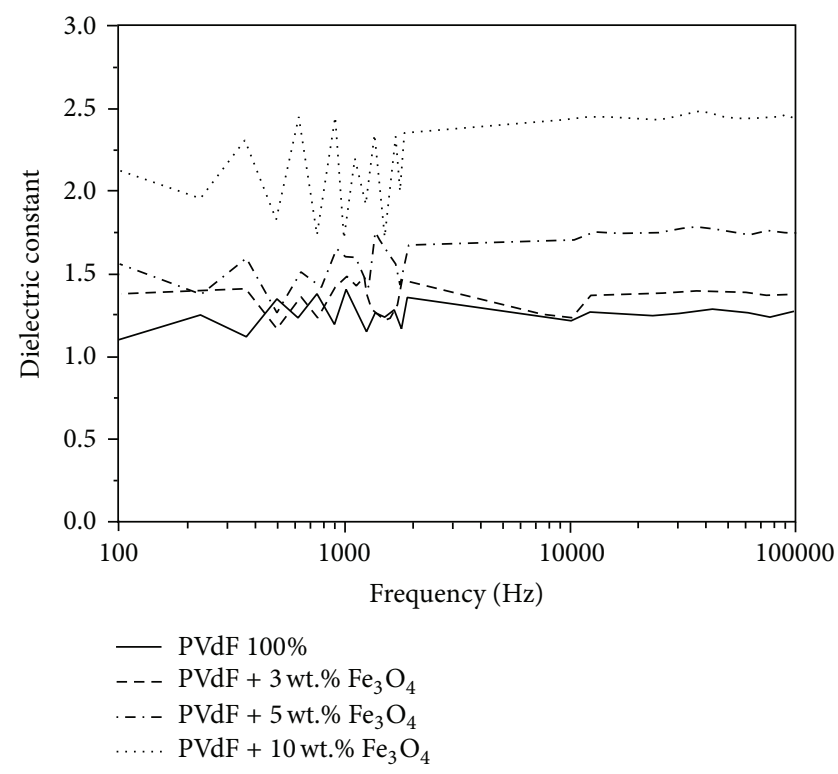

FIGURE 4: Dielectric constant of $\mathrm{PVdF} / \mathrm{Fe}_{3} \mathrm{O}_{4}$ fibre webs as a function of $\mathrm{Fe}_{3} \mathrm{O}_{4}$ nanoparticle content.

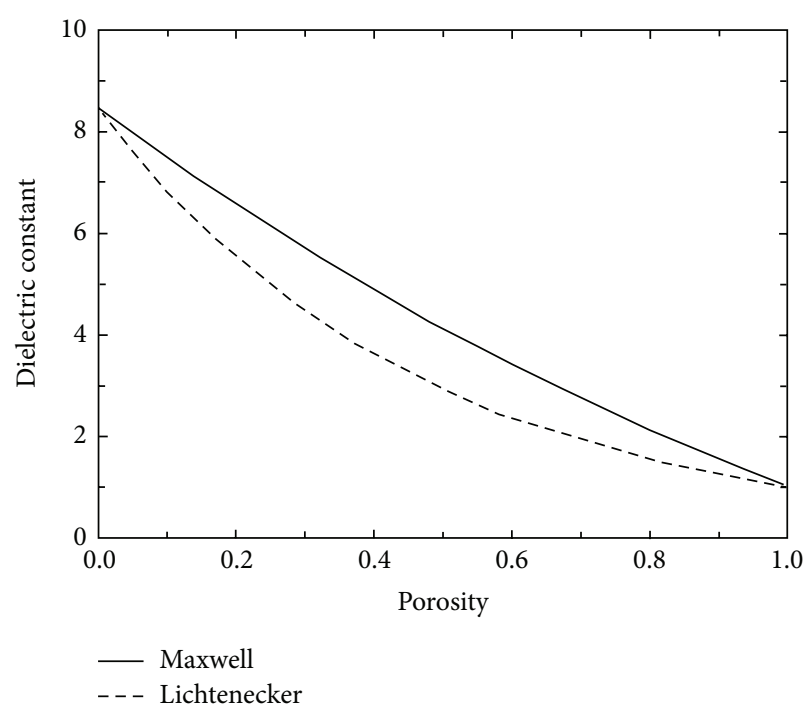

FIGURE 5: Calculated values of dielectric constant for electrospun $\mathrm{PVdF} / \mathrm{Fe}_{3} \mathrm{O}_{4}$ fibre webs as a function of web porosity based on the Maxwell and Lichtenecker mixing models.

accordance with the results obtained for nanocomposite films reported by Nunomura et al. [48].

The experimental dielectric constant for each electrospun web was compared with corresponding calculated data obtained from the mixing models of Maxwell (see (3)) and Lichtenecker (see (4)). The dielectric constant of the bulk PVdF material was found to be 9.0 at $10 \mathrm{kHz}$, and therefore all calculated values were compared with the corresponding measured data at $10 \mathrm{kHz}$. The relationship between the experimental and theoretical data was of the form (Figure 6):

$$
\begin{aligned}
\text { Maxwell } & y=0.786 x+0.6512, \\
\text { Lichtenecker } & y=e^{(0.4589 x+0.7412)}
\end{aligned}
$$




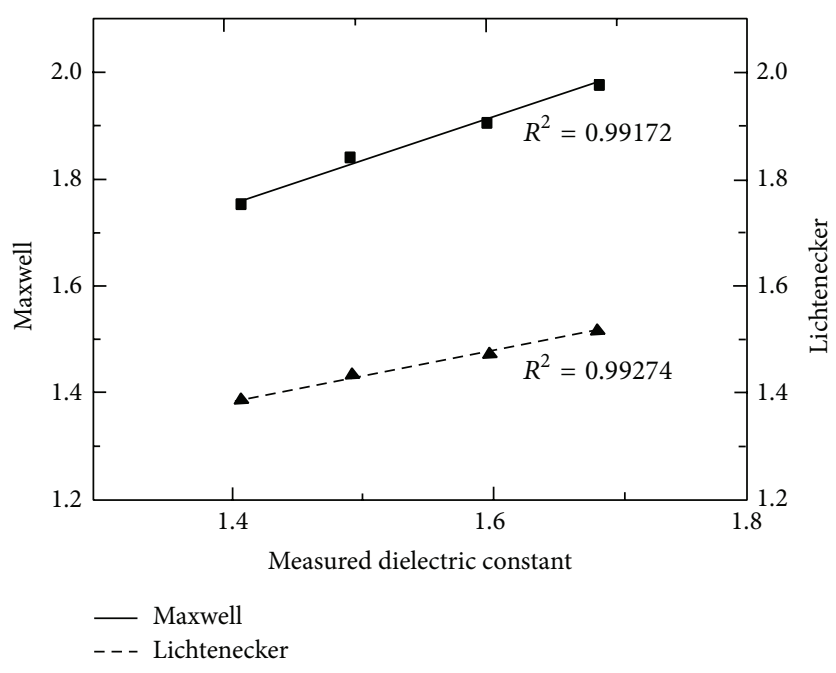

FIGURE 6: Correlation of predicted and measured dielectric constant based on the theoretical mixing models of Maxwell and Lichtenecker.

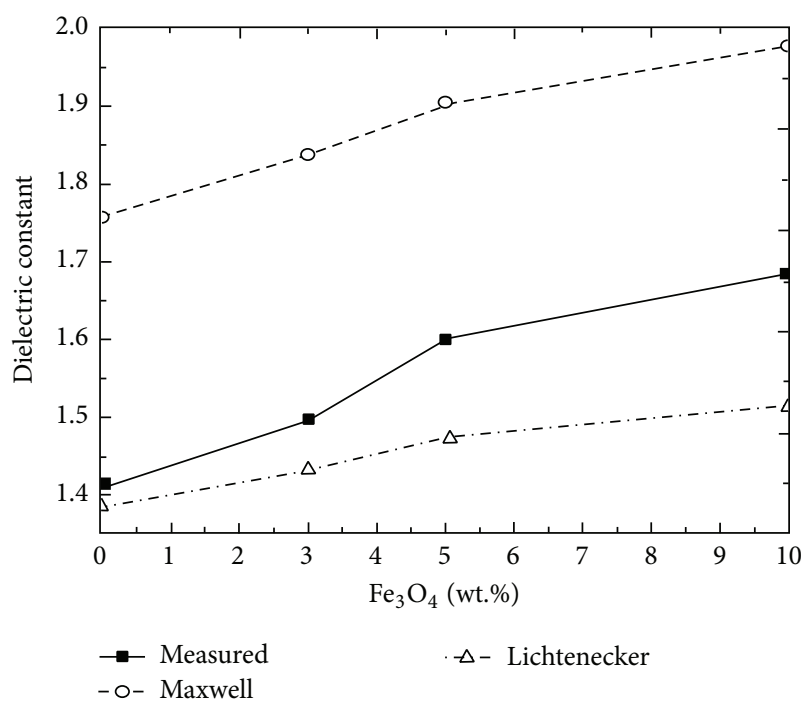

Figure 7: Actual and theoretical dielectric constants of electrospun $\mathrm{PVdF} / \mathrm{Fe}_{3} \mathrm{O}_{4}$ fibre webs in relation to $\mathrm{Fe}_{3} \mathrm{O}_{4}$ nanoparticle content. Theoretical values are based on Maxwell and Lichtenecker mixture equations.

The absolute dielectric constants obtained from the Lichtenecker model were slightly lower than that of Maxwell and were found to be in closest agreement to the experimental data. Previously, the Maxwell model has been reported to be well suited to materials with uniformly distributed spherical pores [32] as compared to the more randomly connected pores present in the as-spun webs. The experimentally observed trend of increasing dielectric constant with increasing $\mathrm{Fe}_{3} \mathrm{O}_{4}$ content (Figure 3) was also found to be in reasonable agreement with the model of Lichtenecker as compared to that of Maxwell (Figure 7).

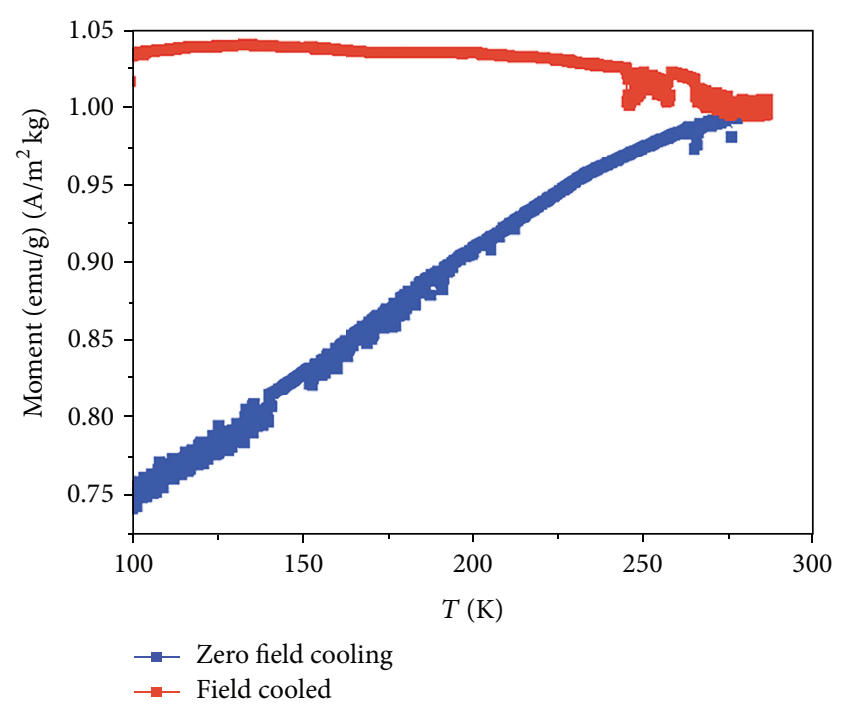

FIgURE 8: ZFC and FC measurements of $\mathrm{PVdF} / \mathrm{Fe}_{3} \mathrm{O}_{4}(5 \%)$ fibre web at $25 \mathrm{mT}$.

In the study of the dielectric behaviour of PVdF$\mathrm{TeFE} / \mathrm{Fe}_{3} \mathrm{O}_{4}$ electrospun webs, Yang [23] also found reasonable agreement with the model of Lichtenecker. Note that the dielectric constant and electrical conductivity of $\mathrm{Fe}_{3} \mathrm{O}_{4}$ nanoparticles at high frequency differ from the bulk values obtained for the web because of the insulating environment of the surrounding voids. However, the dielectric constant can be expected to remain roughly constant with small electrical losses up to several $\mathrm{GHz}$ in the microwave region [49].

3.3. Magnetic Behaviour. Zero field cooled-field cooled measurements at $25 \mathrm{mT}$ revealed the typical magnetisation response of magnetic nanoparticles with a blocking temperature above $300 \mathrm{~K}$ (Figure 8). In agreement with the hysteresis loops measured at $285 \mathrm{~K}$, this indicates that the material remained ferrimagnetic, rather than superparamagnetic, at room temperature.

This is in agreement with the measured coercive field of some $8 \mathrm{mT}$ (see inset in Figure 9). The corresponding particle size would be anticipated to be of the order of $40 \mathrm{~nm}$ [50]. This further suggests that there was agglomeration and dipolar interaction between the nanoparticles in the constituent fibres, and the estimated $40 \mathrm{~nm}$ particle size based on the VSM data was in good agreement with the mean particle size value of $39.2 \mathrm{~nm}$ obtained from the TEM measurements. The VSM results in Figure 9 indicate the values of specific magnetic saturation of $\mathrm{PVdF}$ and the electrospun materials containing 3-10 wt $\% \mathrm{Fe}_{3} \mathrm{O}_{4}$. As expected, the increase in saturation magnetisation was roughly linear with the $\mathrm{Fe}_{3} \mathrm{O}_{4}$ content. The specific magnetic saturation was relatively low for these nanoparticles when compared with the bulk because of the dipolar interaction and the formation of larger magnetic domains in bulk.

Previously, $\mathrm{Fe}_{3} \mathrm{O}_{4}$ nanoparticles have been found to be single domain below $50 \mathrm{~nm}$ and not superparamagnetic until $<23 \mathrm{~nm}$ [51]. Superparamagnetism has been observed in 


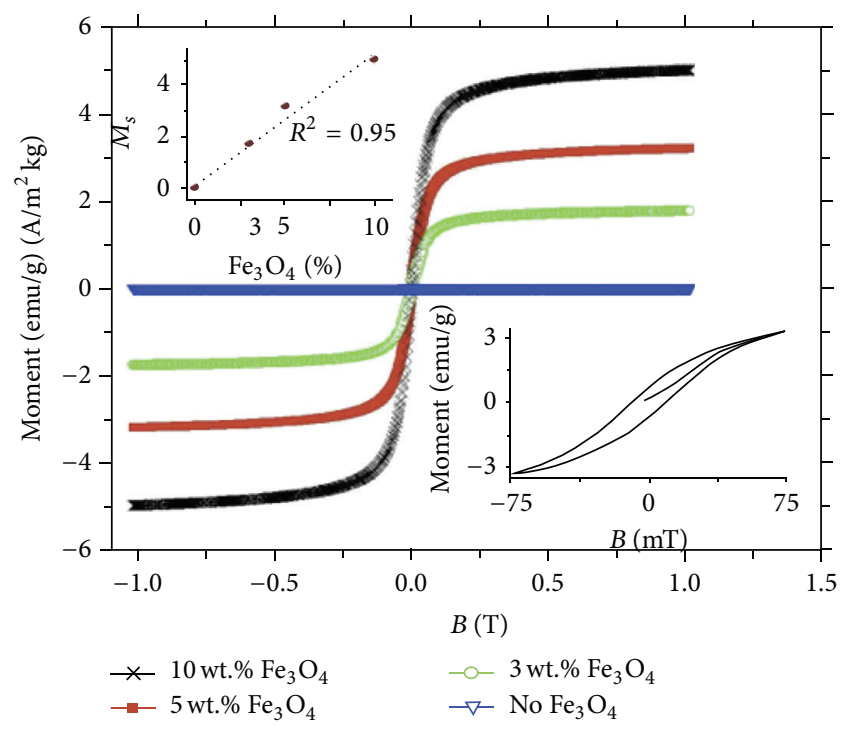

FIGURE 9: Magnetic saturation versus magnetic field for electrospun PVdF fibre webs with $\mathrm{Fe}_{3} \mathrm{O}_{4}$ nanoparticle contents of $0 \mathrm{wt} \%, 3 \mathrm{wt} \%$, $5 \mathrm{wt} \%$, and $10 \mathrm{wt} \%$.

electrospun polymer nanocomposite fibres of PVdF-TeFE with embedded $\mathrm{Fe}_{3} \mathrm{O}_{4}$ [22] particles of 20-30 nm diameter. Similarly, work by Wang et al. [36] on electrospun PAN nanofibre webs containing $8 \mathrm{~nm} \mathrm{Fe} \mathrm{O}_{4}$ nanoparticles demonstrated superparamagnetic behaviour at room temperature. PVP-coated $\mathrm{Fe}_{3} \mathrm{O}_{4}$ nanoparticles electrospun directly to make nanofibre webs with constituent fibre diameters of 200-400 $\mathrm{nm}$ displayed superparamagnetic behavior and the $\mathrm{Fe}_{3} \mathrm{O}_{4}$ nanoparticles showed a saturation magnetisation of $36.6 \mathrm{emu} / \mathrm{g}$ [52].

The increase in embedded mean particle size within the fibres due to agglomeration is likely to mitigate against a transition from ferrimagnetic to superparamagnetic behavior. The increased mean size of the nanoparticles as a result of agglomeration therefore had the effect of maintaining residual ferrimagnetism in the electrospun $\mathrm{PVdF} / \mathrm{Fe}_{3} \mathrm{O}_{4}$ web assembly. The potential for relatively high magnetic field strength in ferrimagnetic $\mathrm{PVdF} / \mathrm{Fe}_{3} \mathrm{O}_{4}$ webs could provide significant potential for their integration within cost-effective filtration and separation media to increase the efficiency of suspended particle removal from fluid streams.

\section{Conclusions}

The purpose of this study was to develop a detailed understanding of the dielectric and specific magnetic saturation properties of pristine $\mathrm{PVdF}$ and $\mathrm{Fe}_{3} \mathrm{O}_{4}$ electrospun fibre webs to inform the assembly of improved liquid filtration and separation media in the future. The dielectric behaviour of the fibre web was found to be influenced by the $\mathrm{Fe}_{3} \mathrm{O}_{4}$ nanoparticle content and the overall web porosity. $\mathrm{PVdF} / \mathrm{Fe}_{3} \mathrm{O}_{4}$ nanocomposite fibre webs were prepared by electrospinning using a dimethylacetamide solvent system. The $\mathrm{Fe}_{3} \mathrm{O}_{4}$ nanoparticles were successfully embedded into the fibres, but particle agglomerations of up to $90 \mathrm{~nm}$ diameter were observed. Agglomeration of the $\mathrm{Fe}_{3} \mathrm{O}_{4}$ nanoparticles in the fibres promoted ferrimagnetic rather than superparamagnetic behaviour in the fibre web and the magnetic field saturation increased linearly by increasing the $\mathrm{Fe}_{3} \mathrm{O}_{4}$ nanoparticle content. The dielectric constant of the electrospun webs increased up to $80 \%$ by the addition of a $10 \mathrm{wt} \%$ of $\mathrm{Fe}_{3} \mathrm{O}_{4}$ nanoparticles and was also influenced by web porosity. Of the Lichtenecker and Maxwell mixing models, the former was found to give values that were in closest agreement with experimentally determined dielectric constants of the electrospun $\mathrm{PVdF} / \mathrm{Fe}_{3} \mathrm{O}_{4}$ webs.

\section{Conflict of Interests}

The authors declare that there is no conflict of interests regarding the publication of this paper.

\section{References}

[1] A. Mario, M. D. S. Perez, and J. W. Louks, U.S. Patent 6, 432, 532, 2001.

[2] S. J. Mahajan, B. L. Deopura, and Y. Wang, "Fibrillation behavior of oriented tapes of polyethylene and its blends. IV," Journal of Applied Polymer Science, vol. 60, no. 10, pp. 1551-1560, 1996.

[3] R. D. Pike, US Patent 5, 935, 883, 1999.

[4] C. J. Ellison, A. Phatak, D. W. Giles, C. W. Macosko, and F. S. Bates, "Melt blown nanofibers: fiber diameter distributions and onset of fiber breakup," Polymer, vol. 48, no. 11, pp. 3306-3316, 2007.

[5] P. K. Baumgarten, "Electrostatic spinning of acrylic microfibers," Journal of Colloid And Interface Science, vol. 36, no. 1, pp. 71-79, 1971.

[6] L. Larrondo and R. S. J. Manley, "Electrostatic fiber spinning from polymer melts I Experimental observations on fiber formation and properties," Journal of Polymer Science. Part A2, Polymer Physics, vol. 19, no. 6, pp. 909-920, 1981.

[7] D. H. Reneker and I. Chun, "Nanometre diameter fibres of polymer, produced by electrospinning," Nanotechnology, vol. 7, no. 3, pp. 216-223, 1996.

[8] P. X. Ma and R. Zhang, "Synthetic nano-scale fibrous extracellular matrix," Journal of Biomedical Materials Research Part A, vol. 46, pp. 60-72, 1999.

[9] G. Liu, L. Qiao, and A. Guo, "Diblock copolymer nanofibers," Macromolecules, vol. 29, no. 16, pp. 5508-5510, 1996.

[10] L. Feng, S. Li, and H. Li, "Super-hydrophobic surface of aligned polyacrylonitrile fibers," Angewandte Chemie International Edition, vol. 114, pp. 1269-1271, 2002.

[11] J. Lyons, C. Li, and F. Ko, "Melt-electrospinning part I: processing parameters and geometric properties," Polymer, vol. 45, no. 22, pp. 7597-7603, 2004.

[12] D. Li, T. Herricks, and Y. Xia, "Magnetic nanofibers of nickel ferrite prepared by electrospinning," Applied Physics Letters, vol. 83, no. 22, pp. 4586-4588, 2003.

[13] J. Xiang, X.-Q. Shen, F.-Z. Song, and M.-Q. Liu, "Fabrication and magnetic properties of $\mathrm{Ni}_{0.5} \mathrm{Zn}_{0.5} \mathrm{Fe}_{2} \mathrm{O}_{4}$ nanofibres by electrospinning," Chinese Physics $B$, vol. 18, no. 11, pp. 4960 4965, 2009.

[14] C.-J. Li and J.-N. Wang, "Electrospun $\mathrm{SrRe}_{0.6} \mathrm{Fe}_{11.4} \mathrm{O}_{19}$ magnetic nanofibers: fabrication and characterization," Materials Letters, vol. 64, no. 5, pp. 586-588, 2010. 
[15] W. Ponhan and S. Maensiri, "Fabrication and magnetic properties of electrospun copper ferrite $\left(\mathrm{CuFe}_{2} \mathrm{O}_{4}\right)$ nanofibers," Solid State Sciences, vol. 11, no. 2, pp. 479-484, 2009.

[16] H. Wu, R. Zhang, X. Liu, D. Lin, and W. Pan, "Electrospinning of Fe, Co, and Ni nanofibers: synthesis, assembly, and magnetic properties," Chemistry of Materials, vol. 19, no. 14, pp. 3506-3511, 2007.

[17] M. Chung, S.-F. Ho, and C.-R. Lin, "Electrospun magnetic thin film," in Proceedings of the IEEE Conference on Electron Devices and Solid-State Circuits (EDSSC '07), pp. 309-311, Tainin, Taiwan, December 2007.

[18] M. Wang, H. Singh, T. A. Hatton, and G. C. Rutledge, "Fieldresponsive superparamagnetic composite nanofibers by electrospinning," Polymer, vol. 45, no. 16, pp. 5505-5514, 2004.

[19] M. Rudolph and U. A. Peuker, "Coagulation and stabilization of sterically functionalized magnetite nanoparticles in an organic solvent with different technical polymers," Journal of Colloid and Interface Science, vol. 357, no. 2, pp. 292-299, 2011.

[20] D. Zhang, A. B. Karki, D. Rutman et al., "Electrospun polyacrylonitrile nanocomposite fibers reinforced with $\mathrm{Fe}_{3} \mathrm{O}_{4}$ nanoparticles: fabrication and property analysis," Polymer, vol. 50, no. 17, pp. 4189-4198, 2009.

[21] X. Xu, Q. Wang, H. C. Choi, and Y. H. Kim, "Encapsulation of iron nanoparticles with PVP nanofibrous membranes to maintain their catalytic activity," Journal of Membrane Science, vol. 348, no. 1-2, pp. 231-237, 2010.

[22] C. Barrera, K. Hyde, J. P. Hinestroza, T. Gould, G. Montero, and C. Rinaldi, "Electrospun magnetic nanofibers with anti-counterfeiting applications," in Proceedings of the ASME International Mechanical Engineering Congress and Exposition (IMECE '05), pp. 467-473, Orlando, Fla, USA, November 2005.

[23] H. Yang, Fabrication and characterization of multifunctional nanofiber nanocomposite structures through co-electrospinning process [Ph.D. thesis], Drexel University, 2007.

[24] J. S. Andrew and D. R. Clarke, "Effect of electrospinning on the ferroelectric phase content of polyvinylidene difluoride fibers," Langmuir, vol. 24, no. 3, pp. 670-672, 2008.

[25] O. D. Jayakumar, B. P. Mandal, J. Majeed, G. Lawes, R. Naik, and A. K. Tzagi, "Inorganic/organic multiferroic hybrid films of $\mathrm{Fe}_{3} \mathrm{O}_{4}$ and PVDF with significant magneto/dielectric coupling," Journal of Material Chemistry C, vol. 1, pp. 3710-3715, 2013.

[26] H. L. W. Chan, Q. Q. Zhang, W. Y. Ng, and C. L. Choy, "Dielectric permittivity of PCLT/PVDF-TRFE nanocomposites," IEEE Transactions on Dielectrics and Electrical Insulation, vol. 7, no. 2, pp. 204-207, 2000.

[27] J. X. Wen, "Piezoelectricity and pyroelectricity in a copolymer of vinylidene fluoride and tetrafluoroethylene," Polymer Journal, vol. 17, no. 2, pp. 399-407, 1985.

[28] S.-S. Choi, Y. S. Lee, C. W. Joo, S. G. Lee, J. K. Park, and K.-S. Han, "Electrospun PVDF nanofiber web as polymer electrolyte or separator," Electrochimica Acta, vol. 50, no. 2-3, pp. 339-343, 2004.

[29] Y. Ding, P. Zhang, Z. Long, Y. Jiang, F. Xu, and W. Di, "Preparation of PVDF based electrospun membranes and their application as separators," Science and Technology of Advanced Materials, vol. 9, pp. 1-4, 2008.

[30] H. Yang, H. Li, W.-H. Shih, Y. Yamashita, and F. Ko, "Multifunctional nanoparticles reinforced nanofibers by electrospinning," in Proceedings of the 16th International Conference on Composite Materials (ICCM '07), Kyoto, Japan, July 2007.
[31] D. R. Biswas, "Electric properties of porous pzt ceramics," Journal of the American Chemical Society, vol. 61, pp. 461-464, 2006.

[32] H. Kobayashi and Y. Hosokawa, "Dielectric constant characteristics of a new composite dielectric material," Journal of the American Ceramic Society, vol. 73, no. 6, pp. 1774-1776, 1990.

[33] U. Mohideen, T. R. Gururaja, L. E. Cross, and R. Roy, "Ultralow dielectric constant porous silica thick films for high-speed IC packaging," IEEE Transactions on Components, Hybrids and Manufacturing Technology, vol. 11, no. 1, pp. 159-162, 1988.

[34] Q. Xue, "Effective-medium theory for two-phase random composites with an interfacial shell," Journal of Materials Science and Technology, vol. 16, no. 4, pp. 367-369, 2000.

[35] A. P. Venugopal and S. J. Russell, "Assembly and characterisation of PVdF nanofibrous materials with magnetic properties composites," in Proceedings of the 18th Annual International Conference on Composites/Nano Engineering (ICCE '10), Anchorage, Alaska, USA, 2010.

[36] B. Wang, Y. Sun, and H. Wang, "Preparation and properties of electrospun $\mathrm{PAN} / \mathrm{Fe}_{3} \mathrm{O}_{4}$ magnetic nanofibers," Journal of Applied Polymer Science, vol. 115, no. 3, pp. 1781-1786, 2010.

[37] S. J. Park, S. Bhargava, E. T. Bender, G. G. Chase, and R. D. Ramsier, "Palladium nanoparticles supported by alumina nanofibers synthesized by electrospinning," Journal of Materials Research, vol. 23, no. 5, pp. 1193-1196, 2008.

[38] T. He, Z. Zhou, W. Xu, F. Ren, H. Ma, and J. Wang, "Preparation and photocatalysis of $\mathrm{TiO}_{2}$-fluoropolymer electrospun fiber nanocomposites," Polymer, vol. 50, no. 13, pp. 3031-3036, 2009.

[39] M. M. Demir, M. A. Gulgun, Y. Z. Menceloglu et al., "Palladium nanoparticles by electrospinning from poly(acrylonitrile-coacrylic acid)-PdCl2 solutions. Relations between preparation conditions, particle size, and catalytic activity," Macromolecules, vol. 37, no. 5, pp. 1787-1792, 2004.

[40] C. Erisken, D. M. Kalyon, and H. Wang, "A hybrid twin screw extrusion/electrospinning method to process nanoparticleincorporated electrospun nanofibres," Nanotechnology, vol. 19, no. 16, Article ID 165302, 2008.

[41] P. Gupta, R. Asmatulu, R. Claus, and G. Wilkes, "Superparamagnetic flexible substrates based on submicron electrospun estane fibers containing MnZnFe-Ni nanoparticles," Journal of Applied Polymer Science, vol. 100, no. 6, pp. 4935-4942, 2006.

[42] J. Guo, X. Ye, W. Liu, Q. Wu, H. Shen, and K. Shu, "Preparation and characterization of poly(acrylonitrile-co-acrylic acid) nanofibrous composites with $\mathrm{Fe}_{3} \mathrm{O}_{4}$ magnetic nanoparticles," Materials Letters, vol. 63, no. 15, pp. 1326-1328, 2009.

[43] A. Isayev, "Ultrasound assisted continuous process for dispersion of nanofibres and nanotubes in polymers," U.S. Patent 2009/0275689, 2009.

[44] V. Kalra, J. Lee, J. H. Lee et al., "Controlling nanoparticle location via confined assembly in electrospun block copolymer nanofibers," Small, vol. 4, no. 11, pp. 2067-2073, 2008.

[45] H. Wang, H. Tang, J. He, and Q. Wang, "Fabrication of aligned ferrite nanofibers by magnetic-field-assisted electrospinning coupled with oxygen plasma treatment," Materials Research Bulletin, vol. 44, no. 8, pp. 1676-1680, 2009.

[46] N. Ristolainen, P. Heikkilä, A. Harlin, and J. Seppälä, "Electrospun nanofibers prepared by two methods: in situ emulsion polymerized PVA/nanoTiO 2 and mixing of functional-PVA with nano $\mathrm{TiO}_{2}$," Autex Research Journal, vol. 8, no. 2, pp. 35-40, 2008. 
[47] A.-H. Lu, E. L. Salabas, and F. Schüth, "Magnetic nanoparticles: synthesis, protection, functionalization, and application," Angewandte Chemie-International Edition, vol. 46, no. 8, pp. 12221244, 2007.

[48] S. Nunomura, K. Koga, M. Shiratani et al., "Fabrication of nanoparticle composite porous films having ultralow dielectric constant," Japanese Journal of Applied Physics, Part 2, vol. 44, no. 50-52, pp. L1509-L1511, 2005.

[49] P. C. Fannin, C. N. Marin, I. Malaescu, and N. Stefu, "Microwave dielectric properties of magnetite colloidal particles in magnetic fluids," Journal of Physics Condensed Matter, vol. 19, no. 3, Article ID 036104, 2007.

[50] G. F. Goya, T. S. Berquó, F. C. Fonseca, and M. P. Morales, "Static and dynamic magnetic properties of spherical magnetite nanoparticles," Journal of Applied Physics, vol. 94, no. 5, pp. 3520-3528, 2003.

[51] S. Ahmad, U. Riaz, A. Kaushik, and J. Alam, "Soft template synthesis of super paramagnetic $\mathrm{Fe}_{3} \mathrm{O}_{4}$ nanoparticles a novel technique," Journal of Inorganic and Organometallic Polymers and Materials, vol. 19, no. 3, pp. 355-360, 2009.

[52] C.-R. Lin, T.-C. Tsai, M. Chung, and S.-Z. Lu, "Synthesis and characterization of magnetic nanoparticles embedded in polyvinyl pyrrolidone nanofiber film by electrospinning method," Journal of Applied Physics, vol. 105, no. 7, Article ID 07B509, 2009. 

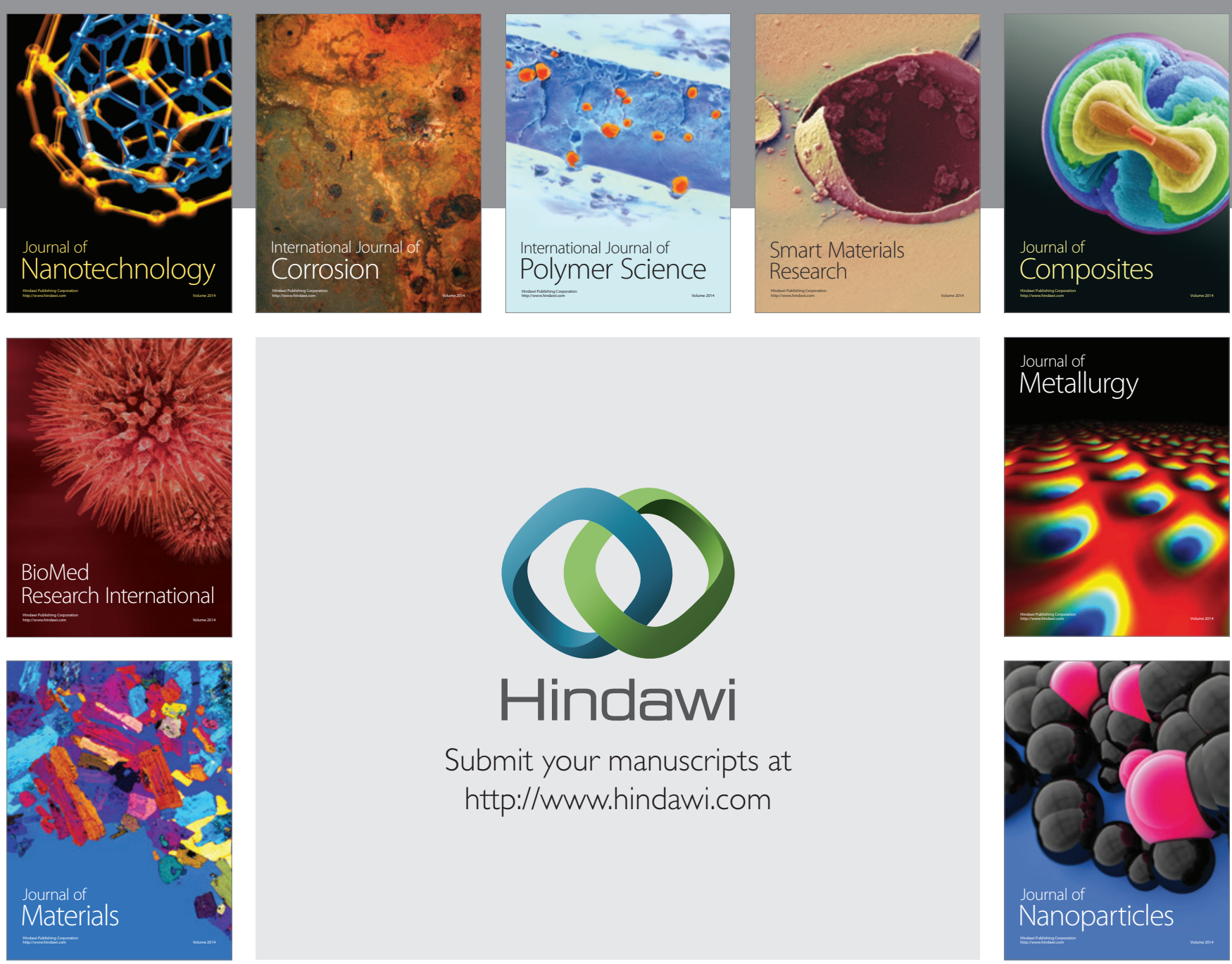

Submit your manuscripts at http://www.hindawi.com
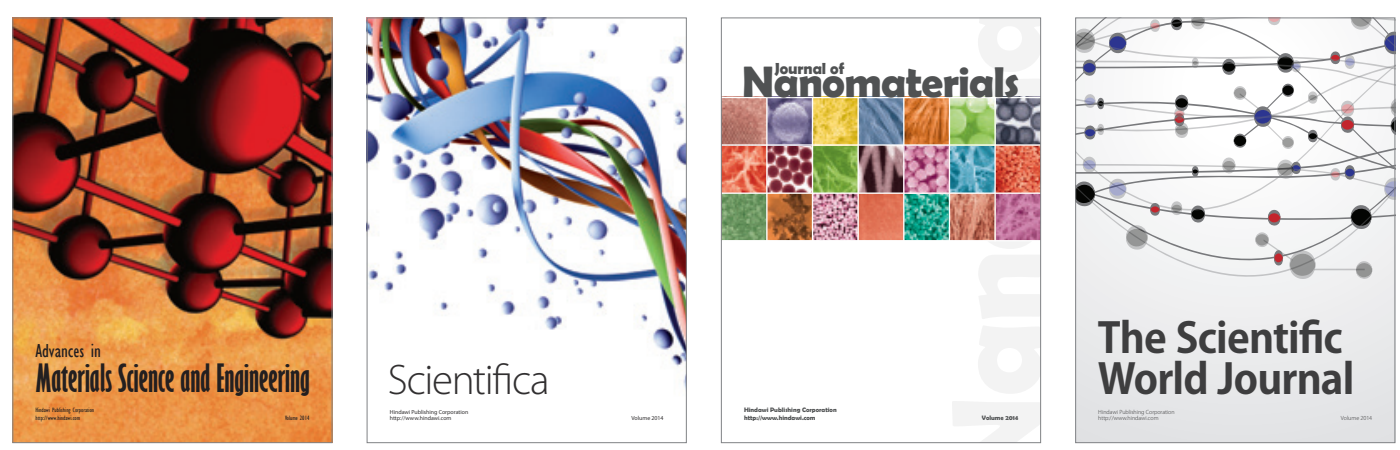

\section{The Scientific World Journal}
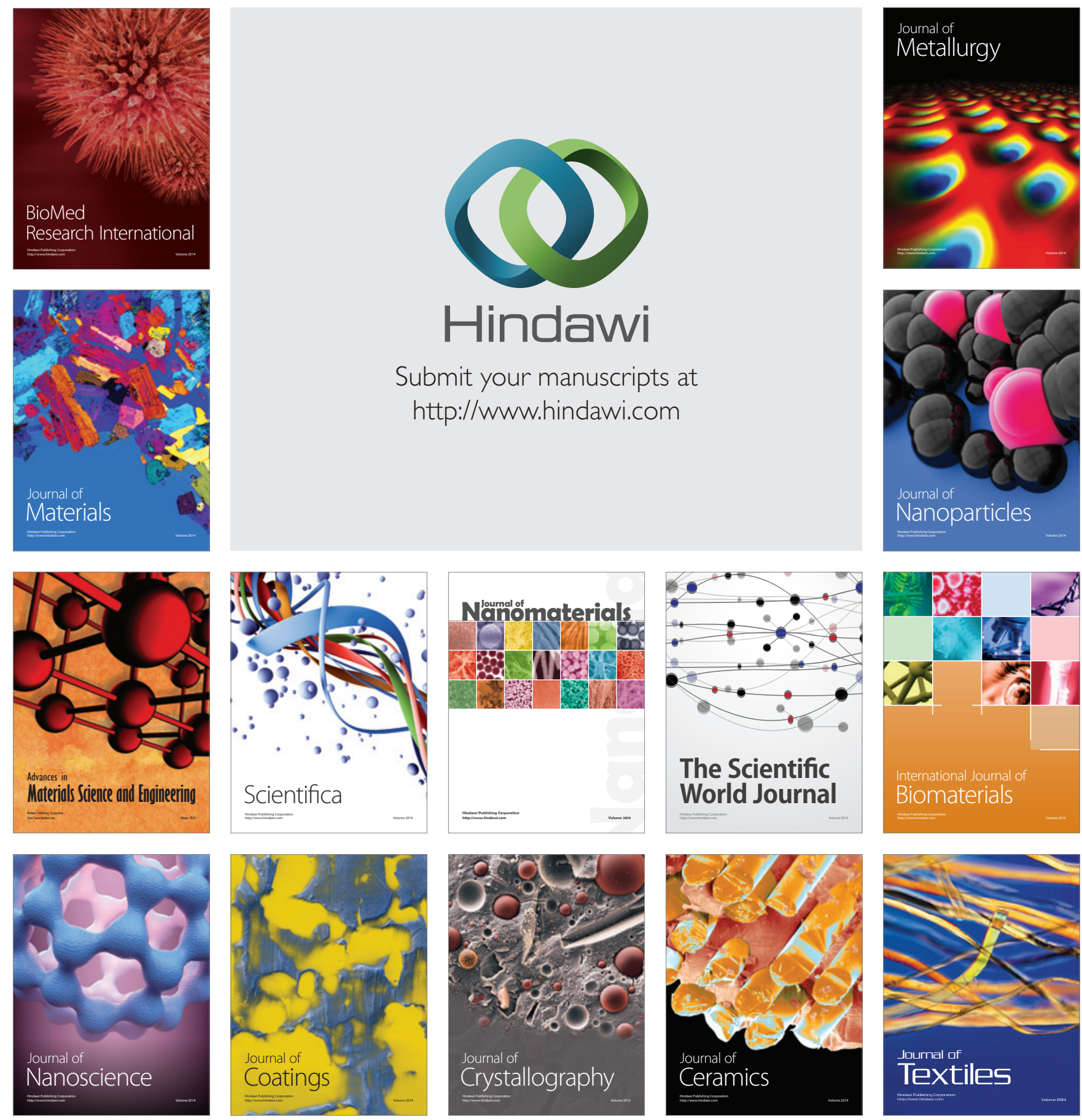